\title{
Forefront Clinical Timeline on Chronic Lymphocytic Leukemia
}

\author{
Kirti Rani \\ ${ }^{1}$ Amity Institute of Biotechnology, Amity University Uttar Pradesh, \\ Noida, UP, India.
}

\begin{abstract}
Hematopoiesis is blood regulatory mechanism which is characterized by a rapid and continuous turnover of blood cells. If this mechanism is disrupted and blood cells can proliferate in uncontrolled manner called, hematopoietic malignancies which is coined leukemia. Leukemia is a kind of neoplastic proliferation of granulocytes or monocytes or lymphocytes or infrequently RBCs and most common type of leukemia is chronic lymphocytic leukemia (CLL). Annually, 15,000 patients are diagnosed for CLL and 5000 deaths due to CLL are reported in United States. Although its diagnostics and therapeutic choices were limited but its treatment has been well improved and clinical selective in the last decade to protracted its remissions or cure in patients.
\end{abstract}

Keywords: Leukemia, Hematopoiesis; Chronic lymphocytic leukemia (CLL)

\section{INTRODUCTION}

Chronic lymphocytic leukemia (CLL) is reported as the most common leukemia diagnosed in the Western world especially in United States. Chemoimmunotherapy is the only standard first-line option clinical accepted approach to treat symptomatic CLL in adults ${ }^{1}$.

Improved cancer biology and molecular diagnostics have resulted in better risk stratification of CLL and to design the clinical strategy of its treatment especially, interpretation of expression of phosphoprotein CD-20 on the surface of B cells. Targeting of this molecule with immunotherapy has led to improved CLL survival rate when used with conventional chemotherapy treatments ${ }^{3}$.

Recently, that most of the CLL patients were observed to have a preceding Monoclonal B Lymphocytes (MBL) phase and with high initial lymphocyte counts that lead to progression to CLL with fast peace ${ }^{4}$. Chronic lymphocytic leukemia does not require any specific adulteration in treatment until associated symptoms develop or the disease progresses causing severe cytopenia ${ }^{5}$.

Various clinical and molecular characteristic features are noticed as the most predictive frame to study clinical course of CLL that can be better used for its risk stratification ${ }^{6}$. And these reported factors or agents were bruton tyrosine kinase inhibitor 'ibrutinib' and the phosphatidylinositol 3-kinase (PI3K) inhibitor 'idelalisib' which include drugs especially, targeting the antiapoptotic protein BCL-232 and anti-CD20 antibodies that lead better CLL cell killing ${ }^{7,8}$.

As per the reported German guidelines, CLL Study Group is classified the CLL patients as fit or unfit based on their renal function on the basis of the cumulative illness rating scale and then, the treatment regimens are further adjusted for the patients ${ }^{8}$. Other recorded studies have been explored for the use of potent immunomodulatory agent e.g. lenalidomide to treat old aged CLL patients as lenalidomide monotherapy on an escalated dosing schedule in combination of geriatric and comorbidity assessments with median follow-up of 4 years which lead to overall survival of $82 \%$ in treated patients ${ }^{9}$.

As well as, accordingly, German CLL Study Group' has been conducted a prospective phase-3 randomized trial comparing chlorambucil alone or with chlorambucil plus either rituximab or obinutuzumab in CLL patients who had coexisting morbidities due to have defined decreased glomerular filtration rate ${ }^{10}$. Those CLL patients who were observed for less responding to the steroid treatment, the use of cyclosporine or mycophenolate with the moderate combination of rituximab, cyclophosphamide and dexamethasone were found to be proved effective to treat CLL patients those have associated unmanageable AIHA (Autoimmune Hemolytic Anemia) ${ }^{11}$. 


\section{CONClusion}

This precise short-review article can be very useful to define the clinical outline of Chronic lymphocytic leukemia (CLL) with expected clinical predictions of its associated prognostic factors and improved conventional treatment in future prospective clinical trials.

\section{ACKNOWLEDGMENT}

I would like to express my cordially appreciation to Amity University Uttar Pradesh, Noida (INDIA).

\section{REFERENCES}

[1] Siegel R, Ma J, Zou Z, Jemal A. Cancer statistics. CA Cancer J Clin. 2014;64(1):9-29.

[2] Hallek M1, Fischer K, Fingerle-Rowson G, Fink AM, Busch R, Mayer J, Hensel M, Hopfinger G, Hess G, von Grünhagen U, Bergmann M, Catalano J, Zinzani PL, Caligaris-Cappio F, Seymour JF, Berrebi A, Jäger U, Cazin B, Trneny M, Westermann A, Wendtner CM, Eichhorst BF, Staib P, Bühler A, Winkler D, Zenz T, Böttcher S, Ritgen M, Mendila M, Kneba M, Döhner H, Stilgenbauer S. Addition of rituximab to fludarabine and cyclophosphamide in patients with chronic lymphocytic leukaemia: a randomised, open-label, phase 3 trial. Lancet. 2010;376(9747):1164-1174

[3] Landgren O1, Albitar M, Ma W, Abbasi F, Hayes RB, Ghia P, Marti GE, Caporaso NE. B-cell clones as early markers for chronic lymphocytic leukemia. N Engl J Med. 2009;360(7):659-667

[4] Hallek M, Cheson BD, Catovsky D, Caligaris-Cappio F, Dighiero G, Döhner H, Hillmen P, Keating MJ, Montserrat E, Rai KR, Kipps TJ. Guidelines for the diagnosis and treatment of chronic lymphocytic leukemia: a report from the International Workshop on Chronic Lymphocytic Leukemia updating the National Cancer Institute Working Group 1996 guidelines. Blood. 2008;111 (12):5446-5456.

[5] Cramer P, Hallek M. Prognostic factors in chronic lymphocytic leukemia-what do we need to know? Nat Rev Clin Oncol. 2011;8(1):38-47

[6] Richard R. Furman, M.D., Jeff P. Sharman, M.D., Steven E. Coutre, M.D., Bruce D. Cheson, M.D., John M. Pagel, M.D., Ph.D., Peter Hillmen, M.B., Ch.B., Ph.D., Jacqueline C. Barrientos, M.D., Andrew D. Zelenetz, M.D., Ph.D., Thomas J. Kipps, M.D., Ph.D., Ian Flinn, M.D., Ph.D., Paolo Ghia, M.D., Ph.D., Herbert Eradat, M.D., Thomas Ervin, M.D., Nicole Lamanna, M.D., Bertrand Coiffier, M.D., Ph.D., Andrew R. Pettitt, Ph.D., F.R.C.Path., Shuo Ma, M.D., Ph.D., Stephan Stilgenbauer, M.D., Paula Cramer, M.D., Maria Aiello, M.A., Dave M. Johnson, B.S., Langdon L. Miller, M.D., Daniel Li, Ph.D., Thomas M. Jahn, M.D., Ph.D., Roger D. Dansey, M.D., Michael Hallek, M.D., and Susan M. O'Brien, M.D. Idelalisib and rituximab in relapsed chronic lymphocytic leukemia. N Engl J Med. 2014;370(11): 997-1007

[7] Wiestner A. Targeting B-Cell receptor signaling for anticancer therapy: the Bruton's tyrosine kinase inhibitor ibrutinib induces impressive responses in B-cell malignancies. $J$ Clin Oncol. 2013;31(1):128-130.

[8] Hallek M. Signaling the end of chronic lymphocytic leukemia: new frontline treatment strategies. Blood. 2013;122(23):3723-3734

[9] Gribben JG. How I treat CLL up front. Blood. 2010; 115(2):187-197.

[10] Valentin Goede, M.D., Kirsten Fischer, M.D., Raymonde Busch, M.S., Anja Engelke, M.D., Barbara Eichhorst, M.D., Clemens M. Wendtner, M.D., Tatiana Chagorova, M.D., Javier de la Serna, M.D., Marie-Sarah Dilhuydy, M.D., Thomas Illmer, M.D., Stephen Opat, M.D., Carolyn J. Owen, M.D., Olga Samoylova, M.D., Karl-Anton Kreuzer, M.D., Stephan Stilgenbauer, M.D., Hartmut Döhner, M.D., Anton W. Langerak, Ph.D., Matthias Ritgen, M.D., Michael Kneba, M.D., Elina Asikanius, M.Sc., Kathryn Humphrey, B.Sc., Michael Wenger, M.D., and Michael Hallek, M.D. Obinutuzumab plus chlorambucil in patients with CLL and coexisting conditions. N Engl J Med. 2014; 370(12):1101-1110.

[11] Gupta N, Kavuru S, Patel D, Janson D, Driscoll N, Ahmed S, Rai KR. Rituximab-based chemotherapy for steroid-refractory autoimmune hemolytic anemia of chronic lymphocytic leukemia. Leukemia. 2002; 16(10):2092-2095. 